\title{
A Randomized Controlled Trial of Extra-amniotic Saline Infusion vs Intracervical Dinoprostone Gel for Induction of Labor
}

\author{
${ }^{1}$ Steffi V Rodrigues, ${ }^{2} \mathrm{MK}$ Swamy, ${ }^{3}$ Namrata Jadhav
}

\section{ABSTRACT}

Background: Success of induction depends largely on cervical ripening and increases the likelihood of vaginal delivery. This study compared the outcomes for induction of labor using extraamniotic saline infusion (EASI) vs intracervical dinoprostone gel. Objective:

Primary: To compare improvement between pre- and postinduction Bishop's scores in both the groups.

Secondary: To compare induction to delivery interval, mode of delivery, and neonatal outcome in both the groups.

Materials and methods: A randomized controlled trial of 1 year was conducted in the Department of Obstetrics and Gynaecology, Karnataka Lingayat Education University Dr Prabhakar Kore Hospital and Medical Research Centre, Belagavi, Karnataka, India, on 82 pregnant women from January 2014 to December 2014. The selected women were divided into two groups of 41 each as group I (induced with dinoprostone) and group II (induced with EASI using Foley's catheter).

Results: Significantly higher number of women had postinduction Bishop's scores between 9 and 12 in the dinoprostone group $(70.73 \% ; p<0.001)$. The mean Bishop's scores were significantly high in the dinoprostone gel $(9.27 \pm 3.07)$ vs EASI $(8.22 \pm 2.34$; $p=0.086$ ). Cervical ripening based on cut-off score of $\geq 6$ was noted in a significantly higher number of women $(92.68 \%)$ in EASI $(p=0.241)$. The mean time for cervical ripening was significantly high in dinoprostone gel group compared with EASI $(15.44 \pm 8.41$ vs $3.88 \pm 3.67 ; p<0.001)$, but mean induction to delivery time was comparable $(p=0.086)$. Significantly higher numbers of vaginal deliveries were noted in dinoprostone group $(91.43 \% ; p=0.001)$. The neonatal outcomes, i.e., birth weight, mean birth weight, appearance, pulse, grimace, activity, and respiration score at 1 and 5 minutes, and neonatal intensive care unit admission, were comparable $(p=0.570)$.

Conclusion: Dinoprostone gel and EASI using Foley's catheter appear to be effective methods for cervical ripening and labor induction, but dinoprostone gel yielded significantly higher rate of vaginal delivery.

Keywords: Cervical ripening, Dinoprostone gel, Extra-amniotic saline infusion, Foley's catheter.

How to cite this article: Rodrigues SV, Swamy MK, Jadhav N. A Randomized Controlled Trial of Extra-amniotic Saline Infusion vs Intracervical Dinoprostone Gel for Induction of Labor. Int J Gynecol Endsc 2017;1(1):11-17

\footnotetext{
${ }^{1}$ Senior Resident, ${ }^{2}$ Professor, ${ }^{3}$ Assistant Professor

${ }^{1-3}$ Department of Obstetrics and Gynaecology, Jawaharlal Nehru Medical College, Karnataka Lingayat Education University, Belagavi, Karnataka, India

Corresponding Author: Steffi V Rodrigues, Senior Resident Department of Obstetrics and Gynaecology, Jawaharlal Nehru Medical College, Karnataka Lingayat Education University Belagavi, Karnataka, India, e-mail: steffirodrigues_88@yahoo.in
}

Source of support: Nil

Conflict of interest: None

\section{INTRODUCTION}

The goal of obstetrics is a pregnancy that results in a healthy infant and a healthy mother. In the majority of women, labor starts spontaneously, and it results in vaginal delivery at or when the term is near. Cervical ripening and induction of labor are often required if there are any medical or obstetric complications of pregnancy. Induction of labor is indicated when the benefits to either the mother or fetus outweigh those of continuing the pregnancy. ${ }^{1}$

Induction rates are increasing disproportionately, accounting for 10 to $30 \%$ of inductions in some countries. ${ }^{2-4}$

Success of induction largely depends on cervical status. ${ }^{5}$ Several methods have been formulated to ripen the cervix, and this process has been described as preinduction cervical ripening. Methods to ripen the cervix include intracervical prostaglandins (dinoprostone) and extra-amniotic saline infusion (EASI) using Foley's catheter.

\section{OBJECTIVE}

\section{Primary}

To compare improvement between pre- and postinduction Bishop's scores in both the groups.

\section{Secondary}

To compare induction to delivery interval, mode of delivery, and neonatal outcome in both the groups.

\section{MATERIALS AND METHODS}

The present study was conducted in the Department of Obstetrics and Gynaecology, Karnataka Lingayat Education University Dr. Prabhakar Kore Hospital and Medical Research Centre, Belagavi, India, during the period from January 2014 to December 2014.

\section{Study Design}

The study design was a randomized controlled trial. 


\section{Study Period and Duration}

The present study was conducted from January 2014 to December 2014.

\section{Place}

This study was conducted at Department of Obstetrics and Gynaecology, Karnataka Lingayat Education University Dr. Prabhakar Kore Hospital and Medical Research Centre, Belagavi, India, a teaching hospital attached to Jawaharlal Nehru Medical College, Belagavi, Karnataka, India.

\section{Source of Data}

Singleton pregnancies between 37 and 42 weeks of gestations, eligible for induction of labor at the Department of Obstetrics and Gynaecology, Karnataka Lingayat Education University Dr Prabhakar Kore Hospital and Medical Research Centre, Belagavi, India, were enrolled.

\section{Sample Size}

A total of 82 pregnant women between 37 and 42 weeks of gestations, eligible for induction of labor divided into two groups of 41 each were studied.

The sample size was calculated by considering Bishop's score of $\leq 6$, with type I error rate $\alpha=0.05$ and type error $\beta=0.02$ and power of $80 \%$ sample size was determined considering the following formula.

$$
\mathrm{n}=\frac{\left(\mathrm{Z}_{\alpha}+\mathrm{Z}_{\beta}\right)^{2} \times \mathrm{p} \times \mathrm{q}}{\left(\mathrm{p}_{0}-\mathrm{p}_{1}\right)^{2}}
$$

where $Z_{\alpha}=1.96 ; Z_{\beta}=0.84 ; p_{0}=67 \% ; p_{1}=36 \%$.

Hence, sample size was taken as 41 in each group, totaling to a sum of 82 cases.

\section{Selection Criteria}

\section{Inclusion}

- Pregnant women with singleton pregnancy with 37 to 42 weeks of gestation

- Cephalic presentation

- Intact membranes

- Reassuring fetal heart rate tracing

- Bishop's score less than 6

\section{Exclusion}

Pregnant women with

- Spontaneous labor

- Multiple gestation

- Malpresentation

- Antepartum hemorrhage

- Previous cesarean delivery

- Gestational diabetes mellitus
- Pregnancy-induced hypertension

- Nonreassuring fetal status

- Known sensitivity to prostaglandins

- Latex allergy

\section{Ethical Clearance}

The Institutional Ethics Committee of Jawaharlal Nehru Medical College, Belagavi, Karnataka, India, approved the study.

\section{Consent Form}

Pregnant women fulfilling selection criteria at Department of Obstetrics and Gynaecology at Karnataka Lingayat Education University Dr Prabhakar Kore Hospital and Medical Research Centre, Belagavi, India, were briefed about the nature of the study, details of the treatment, and a written informed consent was obtained.

\section{Data Collection}

Patients were interviewed for demographic characteristics and obstetric history. Data regarding age, obstetric history, and period of gestation were noted on a predesigned and pretested proforma.

\section{Randomization}

Randomization was done by computer-generated random numbers and assigning numbers to both groups. The women were divided into two groups of 41 each as below.

- Group I: Pregnant women in this group underwent cervical ripening using dinoprostone gel.

- Group II: Pregnant women in this group underwent cervical ripening using EASI using Foley's catheter.

\section{Intervention}

Detailed speculum examination was carried out and cervix was swabbed with povidine iodine and normal saline. Preinduction trace was taken for at least 20 minutes.

\section{Group I}

In this group, Dinoprostone gel was injected into the endocervical canal under direct visualization and subjects remained supine for 30 minutes after administration. A postinduction trace of at least 20 minutes was taken. A maximum of three doses of dinoprostone gel was instilled. Amniotomy with oxytocin infusion was used to augment the labor, if Bishop's score was 6 or more. Bishop's score was assessed at 8,16 , and 24 hours postinduction.

\section{Group II}

Preinduction trace was taken for at least 20 minutes. A sterile speculum examination was done and cervix was 
prepared with betadine. A 14-gauge Foley's catheter was inserted beyond the internal os under direct visualization. Balloon was inflated with $30 \mathrm{~mL}$ sterile water, and normal saline was infused through the catheter. Totally, a maximum of $200 \mathrm{~mL}$ of saline was infused. The cervix was assessed for Bishop's score at 8 hours or when the catheter was expelled. If Bishop's score remained less than 6, catheter was continued for another 8 hours or until the catheter was expelled. Amniotomy with oxytocin infusion was used to augment the labor if Bishop's score was 6 or more.

Antibiotics were not given to patients unless there were any signs of infection or cesarean section was performed. For the purpose of analysis, failed induction was defined as labor arrest before $3 \mathrm{~cm}$ of cervical dilatation. Failure to progress was defined as secondary arrest of labor at or beyond $3 \mathrm{~cm}$ dilatation despite adequate uterine contraction for a minimum of 2 hours. Fetal distress was defined as persistent nonreassuring fetal heart sound remote from delivery.

\section{Outcome Variables}

The study population was assessed for the following outcomes:

- Improvement between pre- and postinduction Bishop's score.

- Induction to delivery interval

- Mode of delivery

- Neonatal outcome

\section{Statistical Analysis}

Data obtained were coded and entered into the Microsoft Excel Spreadsheet. The data were analyzed using statistical software Statistical Package for the Social Sciences version 20. The categorical data were expressed in terms of frequencies and percentages, while continuous data were expressed as mean \pm standard deviation.

Table 1: Demographic distribution in both the groups

\begin{tabular}{lll}
\hline Characteristic & $\begin{array}{l}\text { Dinoprostone gel } \\
(n=41)\end{array}$ & $\begin{array}{l}\text { Extra-amniotic } \\
\text { saline infusion } \\
(n=41)\end{array}$ \\
\hline $\begin{array}{lll}\text { Age (years) } \\
20 \text { or less }\end{array}$ & $15(36.59 \%)$ & $13(31.71 \%)$ \\
$21-25$ & $20(48.78 \%)$ & $21(51.22 \%)$ \\
$26-30$ & $5(12.20 \%)$ & $7(17.07 \%)$ \\
31 or more & $1(2.44 \%)$ & $0(0 \%)$ \\
Parity & & \\
Primigravida & $24(58.54 \%)$ & $27(65.85 \%)$ \\
Gravida 2 & $12(29.27 \%)$ & $11(26.83 \%)$ \\
Gravida 3 & $5(12.2 \%)$ & $2(4.88 \%$ \\
Gravida 4 & $0(0)$ & $1(2.44 \%)$ \\
Gestational age (weeks) & & $17(41.46 \%)$ \\
$37-40$ & $20(48.78 \%)$ & $24(58.54 \%)$ \\
$41-42$ & $21(51.22 \%)$ & \\
\hline
\end{tabular}

The two groups were compared using chi-square test for categorical data, and independent sample $t$ test was used to compare the means of different parameters. A p-value of $\leq 0.05$ was considered to be statistically significant.

\section{RESULTS}

- Maximum women in group I (48.78\%) and group II $(51.22 \%)$ were aged between 21 and 25 years $(p=0.829)$ and the mean age in group I (22.27 \pm 3.11 years) and group II $(22.54 \pm 2.88$ years $)$ was comparable $(\mathrm{p}=0.687)$

- Obstetric history revealed that $58.54 \%$ of the women were primigravida in group I compared with $65.85 \%$ of the pregnant women in group II ( $p=0.549)$.

- A total of $51.22 \%$ and $58.54 \%$ of the pregnant women had gestational age between 41 and 42 weeks in groups I and II respectively, $(p=0.506)$.

- The demographic characteristics, obstetric history, indications for induction, and preinduction Bishop's score in groups I and II ( $p>0.050)$ were comparable (Tables 1 to 3 and Graphs 1 and 2).

- The postinduction Bishop's scores were between 9 and 12 in significantly higher number of women in group I $(70.73 \%)$ compared with group II $(34.15 \%$; p $<0.001)$.

- In addition, the mean Bishop's score in group I was significantly high $(9.27 \pm 3.07)$ compared with group II $(8.22 \pm 2.34 ; \mathrm{p}=0.086)$.

- Cervical ripening based on cut-off score $\geq 6$ was noted in significantly higher number of women $(92.68 \%)$ in group II compared with group I $(85.37 \%$; $p=0.241)$ (Table 4 and Graph 3).

- Significantly higher number of women in group II $(88.47 \%)$ had cervical ripening within 8 hours from the induction compared with group I $(42.86 \%$; $<<0.001)$ and the mean time for cervical ripening time was significantly high in group I (15.44 \pm 8.41 hours) compared with group II $(3.88 \pm 3.67 ; \mathrm{p}<0.001)$.

Table 2: Preinduction Bishop's score

\begin{tabular}{lll}
\hline Score & $\begin{array}{l}\text { Dinoprostone gel } \\
(n=41)\end{array}$ & $\begin{array}{l}\text { Extra-amniotic saline } \\
\text { infusion }(n=41)\end{array}$ \\
\hline 0 & $19(46.34 \%)$ & $22(53.66 \%)$ \\
1 & $2(4.88 \%)$ & $3(7.32 \%)$ \\
2 & $8(19.51 \%)$ & $5(12.20 \%)$ \\
3 & $4(9.76 \%)$ & $2(4.88 \%)$ \\
4 & $8(19.51 \%)$ & $9(21.95 \%)$ \\
\hline
\end{tabular}

Table 3: Postinduction Bishop's score

\begin{tabular}{cll}
\hline Score & $\begin{array}{l}\text { Dinoprostone gel } \\
(n=41)\end{array}$ & $\begin{array}{l}\text { Extra-amniotic saline } \\
\text { infusion }(n=41)\end{array}$ \\
\hline$\leq 4$ & $6(14.63 \%)$ & $0(0)$ \\
$5-8$ & $5(12.20 \%)$ & $26(63.41 \%)$ \\
$9-12$ & $29(70.73 \%)$ & $14(34.15 \%)$ \\
$>12$ & $1(2.44 \%)$ & $1(2.44 \%)$ \\
\hline
\end{tabular}




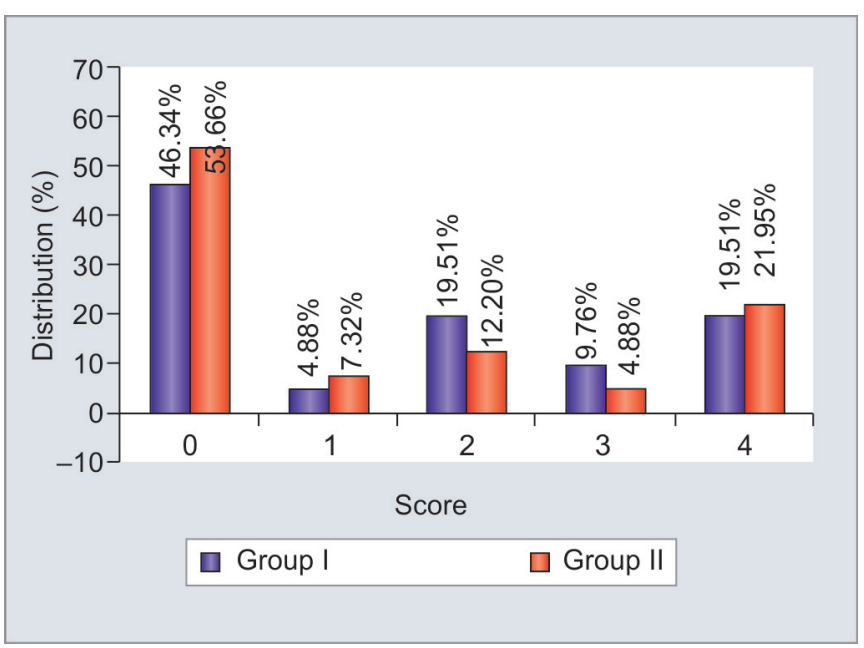

Graph 1: Preinduction Bishop's scores

- The mean induction to delivery time was comparable in group I (17.70 \pm 10.30 hours) and group II $(14.02 \pm 7.69 ; \mathrm{p}=0.086)$ (Table 5 and Graph 4).

- Significantly higher number of vaginal deliveries were noted in group I $(91.43 \%)$ compared with group II (54.26\%; $\mathrm{p}=0.001$ ) (Table 6).

- No statistically significant difference was noted between groups I and II with regard to distribution of babies according to the birth weight $(p=0.570)$, mean birth weight $(p=0.739)$, appearance, pulse, grimace, activity, and respiration (Apgar) score at 1 minute $(p=0.268)$ and 5 minutes, and neonatal intensive care unit (NICU) admissions ( $\mathrm{p}=0.531)$ (Table 7).

Table 4: Mean time for cervical ripening

\begin{tabular}{lll}
\hline Variable & $\begin{array}{l}\text { Dinoprostone gel } \\
(n=35)\end{array}$ & $\begin{array}{l}\text { Extra-amniotic saline } \\
\text { infusion }(n=38)\end{array}$ \\
\hline $\begin{array}{l}\text { Time for cervical } \\
\text { ripening (hours) }\end{array}$ & 15.44 & 3.88 \\
\hline
\end{tabular}

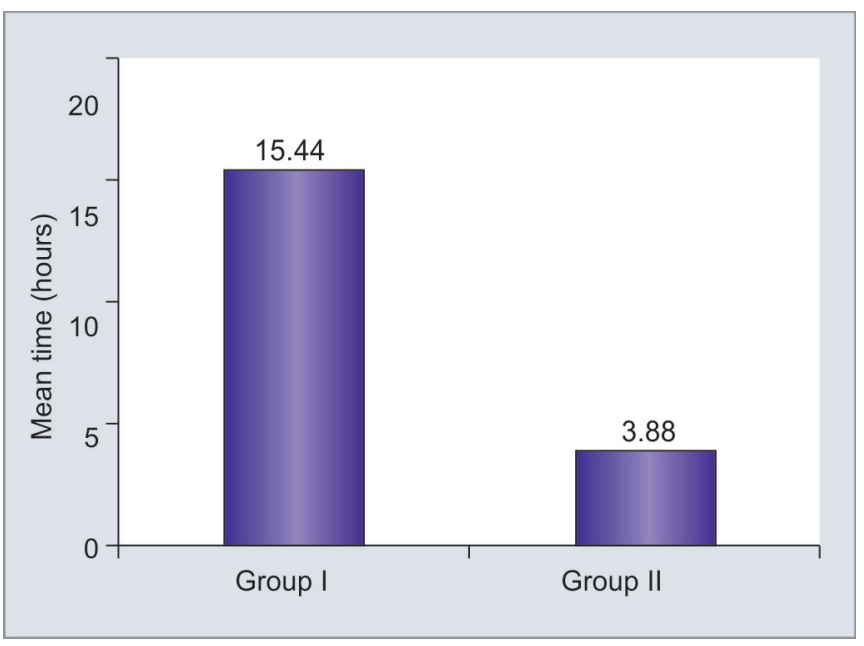

Graph 3: Mean time for cervical ripening

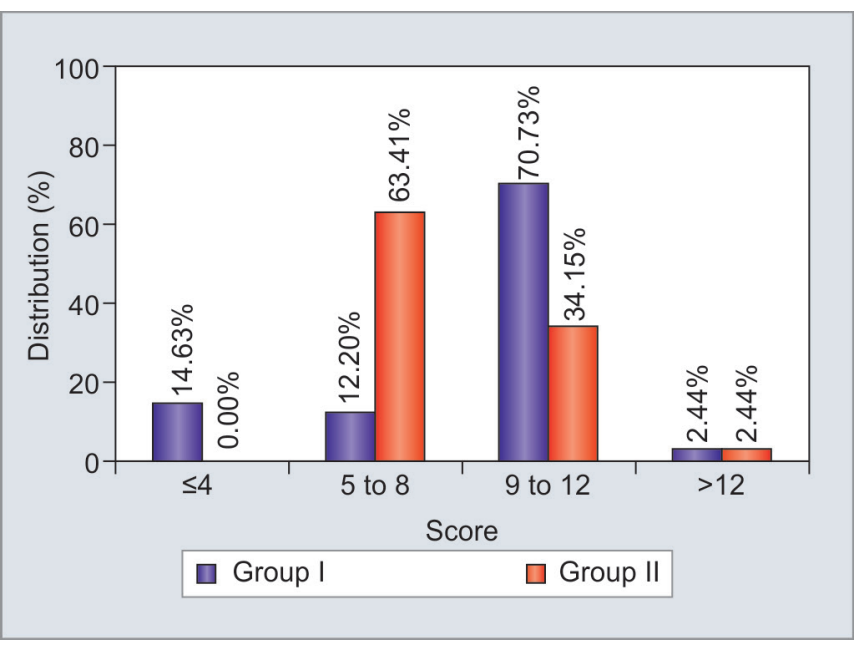

Graph 2: Postinduction Bishop's scores

The EASI using Foley's catheter and dinoprostone gel appeared to be effective methods for cervical ripening and labor induction, but EASI using Foley's catheter results in higher rate of cesarean section.

\section{DISCUSSION}

In the present study, obstetric history including maternal age distribution $(p=0.829)$, mean maternal age $(p=0.687)$, gravida $(\mathrm{p}=0.549)$, gestational age $(\mathrm{p}=0.506)$, mean period of gestation ( $p=0.599)$, indication for induction $(p=0.075)$, and preinduction Bishop's score $(\mathrm{p}=0.780)$, with mean Bishop's scores $(p=0.639)$ comparable in groups I and II. These findings rule out the possible bias in the study results.

Table 5: Mean induction to delivery time

\begin{tabular}{lll}
\hline Variable & $\begin{array}{l}\text { Dinoprostone gel } \\
\left(n=35^{*}\right)\end{array}$ & $\begin{array}{l}\text { Extra-amniotic saline } \\
\text { infusion }\left(n=38^{*}\right)\end{array}$ \\
\hline $\begin{array}{l}\text { Induction to delivery } \\
\text { time (hours) }\end{array}$ & 17.70 & 14.02 \\
\hline
\end{tabular}

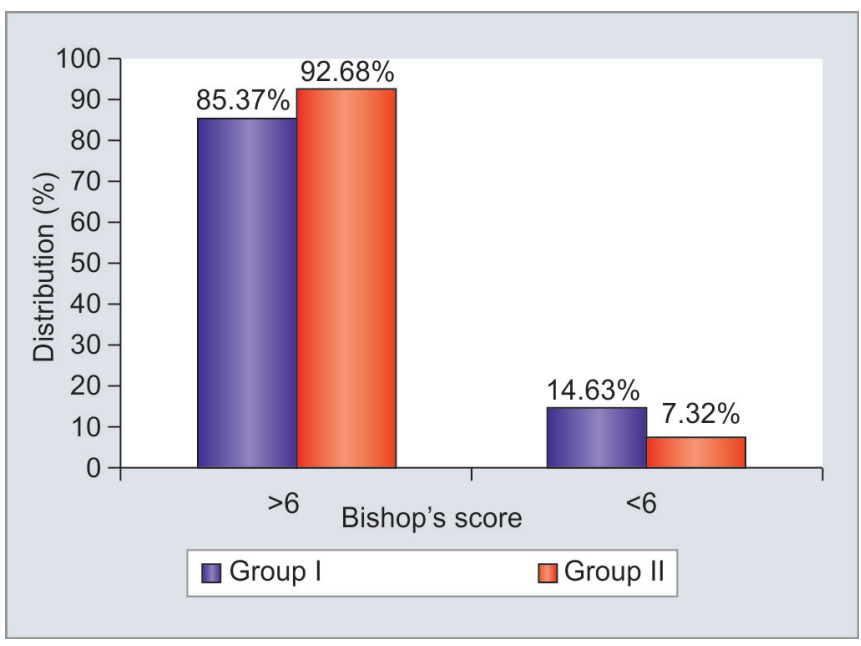

Graph 4: Cervical ripening 


\begin{tabular}{lll}
\hline & \multicolumn{1}{c}{ Table 6: Outcome } & \\
\hline Characteristic & Dinoprostone gel $(n=35)$ & Extra-amniotic saline infusion $(n=38)$ \\
\hline Vaginal birth & $32(91.43 \%)$ & $21(55.26 \%)$ \\
Lower (uterine) segment cesarean section birth & $3(8.57 \%)$ & $17(44.74 \%)$ \\
Birth weight $(\mathrm{kg})$ & & \\
$1.50-1.99$ & $1(2.86 \%)$ & $0(0)$ \\
$2.00-2.49$ & $3(8.57 \%)$ & $5(13.16 \%)$ \\
$2.50-2.99$ & $12(34.29 \%)$ & $10(26.32 \%)$ \\
$3.00-3.49$ & $12(34.29 \%)$ & $18(47.37 \%)$ \\
$\geq 3.5$ & $7(20 \%)$ & $5(13.16 \%)$ \\
Apgar score at 1 minute & & $2(5.26 \%)$ \\
$<7$ & $0(0)$ & $36(94.74 \%)$ \\
7 or more & $35(100 \%)$ & $2(5.26 \%)$ \\
NICU admission & & $36(94.74 \%)$ \\
Yes & $1(2.86 \%)$ & \\
No & $34(97.14 \%)$ & \\
\hline
\end{tabular}

Table 7: Analysis

\begin{tabular}{|c|c|c|c|c|}
\hline & Dinoprostone & Extra-amniotic saline infusion & $p$-value & Inference \\
\hline Age (years) & $22.27 \pm 3.11$ & $22.54 \pm 2.88$ & 0.687 & NS \\
\hline Period of gestation & $40.01 \pm 1.31$ & $39.85 \pm 1.38$ & 0.599 & NS \\
\hline $\begin{array}{l}\text { Time taken for cervical ripening (hours) bulb } \\
\text { expulsion/postinduction treatment }\end{array}$ & $15.44 \pm 8.41$ & $3.88 \pm 3.67$ & $<0.001$ & $S$ \\
\hline Bishop's score & $9.27 \pm 3.07$ & $8.22 \pm 2.34$ & 0.086 & HS \\
\hline Induction to delivery interval (hours) & $17.70 \pm 10.30$ & $14.02 \pm 7.69$ & 0.086 & NS \\
\hline Birth weight $(\mathrm{kg})$ & $3.02 \pm 0.50$ & $2.98 \pm 0.41$ & 0.739 & NS \\
\hline
\end{tabular}

NS: Not significant; S: Significant; HS: Highly significant.

In this study among the pregnant women in group I, the mean postinduction time with dinoprostone gel was high (15.44 \pm 8.41 hours) and the required mean number of dinoprostone gel doses was $2.07 \pm 0.91$, while in group II, the mean expulsion time was low ( $3.88 \pm 3.67$ hours).

In the present study, significantly higher number of women in group I $(70.73 \%)$ had postinduction Bishop's scores between 9 and 12 as compared with group II (34.15\%; $\mathrm{p}<0.001)$. Though the mean Bishop's scores were high in group I $(9.27 \pm 3.07)$ compared with group II $(8.22 \pm 2.34)$ statistically, the difference was not significant $(\mathrm{p}=0.086)$. These findings suggest administration of dinoprostone gel results in favorable Bishop's score, but this finding remains controversial as the mean Bishop's scores were comparable. Similar findings were described by Dahiya et al, ${ }^{6}$ St. Onge and Connors, ${ }^{7}$ and Ezimokhai and Nwabineli. ${ }^{8}$

A randomized, prospective study was conducted by Dahiya et $\mathrm{al}^{6}$ to compare the efficacy of extra-amniotic Foley's catheter with intracervical dinoprostone gel for preinduction cervical ripening. They reported mean change in Bishop's score as $4.18 \pm 1.81$ in women with intracervical extra-amniotic Foley's catheter balloon, inflated with $50 \mathrm{~mL}$ of normal saline as compared with $4.6 \pm 1.48$ in women, who received intracervical dinoprostone gel after 12 hours of initiation of process. Further, no significant difference between the mean changes in the two groups could be established.
A study by St. Onge and Connors ${ }^{7}$ compared the Foley's catheter with prostaglandin gel and found both to be effective in changing the Bishop's score.

In the present study, cervical ripening considered as Bishop's score $\geq 6$ was observed in slightly higher patients who were in group II $(92.68 \%)$ compared with group I $(85.37 \%)$, but the difference was statistically not significant $(p=0.241)$. These findings demonstrate that, the success rate of EASI using Foley's catheter is comparable with dinoprostone gel for the induction of labor. Direct comparison of these results to other studies is limited because of reporting differences; however, some comparisons can be drawn.

Goldman and Wigton ${ }^{9}$ also demonstrated that EASI results in more women achieving favorable Bishop's scores than dinoprostone gel when used for preinduction cervical ripening of an unfavorable cervix. Schreyer et $\mathrm{al}^{10}$ found that $67 \%$ receiving EASI achieved a "significant change" in Bishop's score at 3 hours compared with $39 \%$ who achieved a change of three points or more after 6 hours of intravaginal prostaglandin $\mathrm{E}_{2}$ tablets.

Rouben and Arias ${ }^{11}$ also compared EASI with intravaginal prostaglandins. In their study, $37 \%$ of women who received EASI achieved Bishop's scores of 8 or more at 8 hours compared with $14 \%$ who received prostaglandin.

In a review of 11 reported studies, it has been suggested that ripening efficacy by catheter balloon is similar to, or better than, other methods. ${ }^{12}$ 
In this study, significantly higher number of pregnant women in group II $(89.47 \%)$ had cervical ripening in $\leq 8$ hours compared with group I $(42.86 \%)$. The duration of 9 to 16 hours was noted in only $10.53 \%$ of the pregnant women in group II compared with $22.86 \%$ in group I $(\mathrm{p}<0.001)$. Also, the mean time taken for cervical ripening was significantly less in group II (3.88 \pm 3.67 hours) compared with group I $(15.44 \pm 8.41$ hours; $\mathrm{p}<0.001)$. Furthermore, like lower mean cervical ripening time in group II, the mean induction to delivery time was also low (14.02 \pm 7.69 hours) compared with group I (17.70 \pm 10.30 hours), but the difference was statistically not significant $(\mathrm{p}=0.086)$. Hence, it may be hypothesized that, EASI using Foley's catheter requires significantly shorter duration for cervical ripening compared with dinoprostone gel, but the time required from induction to delivery is similar. Similar findings were reported in a randomized, prospective study by Dahiya et $\mathrm{al}^{6}$ where authors noted similar induction to delivery interval in both groups as $18.51 \pm 8.52$ hours in Foley's catheter group and $18.21 \pm 11.13$ hours in the prostaglandin gel group.

In the present study, cervical ripening failed in six women $(14.63 \%)$ of group I and three women $(7.32 \%)$ in group II, and all these women underwent LSCS. Of the six women in group I, five women $(83.33 \%)$ had failed induction and one woman (16.67\%) had fetal distress. In group II, two women $(66.67 \%)$ had nonprogress of labor and one woman $(33.33 \%)$ had fetal distress.

Some of the advantages of the Foley's catheter compared with other methods of cervical ripening and labor induction are low cost, easy to use, and principally the possibility of using it in women with prior cesarean sections. ${ }^{13}$ In the present study, significantly higher number of vaginal deliveries were noted in group I $(91.43 \%)$ compared with group II $(55.26 \% ; \mathrm{p}=0.001)$. The common causes of LSCS in group II was nonprogress of the labor in 11 of 17 women (64.71\%), while in group I failed induction, fetal distress, and nonprogress of labor were the indications for LSCS in 1 of 3 women $(33.33 \%$ each). In contrast, Dahiya et $\mathrm{al}^{6}$ reported no significant difference between Foley's catheter balloon and locally applied prostaglandin in LSCS delivery rates (10 vs 18\%).

In this study, $34.29 \%$ of the newborns each had birth weight between 3.00 and $3.49 \mathrm{~kg}$ and 2.50 and $2.99 \mathrm{~kg}^{\prime} \mathrm{s}$ in group I. In group II, 47.37 and $26.32 \%$ of the newborns weighed between 3.00 and $3.49 \mathrm{~kg}$ and 2.50 and $2.99 \mathrm{~kg}$, suggesting that the distribution of neonates according to their birth weight was comparable. The mean birth weight was also comparable in groups I and II ( $3.02 \pm 0.50$ vs $2.98 \pm 0.41 \mathrm{~kg}$ 's; $\mathrm{p}=0.739)$. Further at 1 minute, Apgar score was $<7$ in $5.26 \%$ of the babies in group II, while none of the babies had Apgar score of $<7$ in group I and at 5 minutes, all the babies in groups I and II had Apgar score of $>7$ at 5 minutes. In this study, the mean Apgar scores at birth $(p=0.862)$ and at 5 minutes after birth $(p=0.995)$ were comparable between groups I and II. No neonatal complications were observed in both the groups. The NICU admission was required in $2.86 \%$ of the babies in group I compared with $5.26 \%$ in group II ( $p=0.531$ ). These findings suggest that the neonatal outcome after induction of labor with EASI using Foley's catheter was comparable with that of induction of labor with dinoprostone gel. Similar observations were made by Dahiya et $\mathrm{al}^{6}$ who reported that fetal outcome data showed no significant difference between the Foley's catheter and the prostaglandin gel groups with respect to birth weight, 1-minute Apgar scores, and 5-minute Apgar scores. A clinical study by Rashid et a ${ }^{14}$ also found favorable and beneficial effects of Foley's catheter.

Overall, the present study showed that both EASI using Foley's catheter and dinoprostone gel appeared to be effective agents for cervical ripening and labor induction. There was no significant difference in ripening efficacy and perinatal and neonatal outcomes. As more patients are induced for postdatism and other indications, the question of the best method of preinduction cervical ripening remains controversial..$^{15}$ The current study supports both the EASI using Foley's catheter and the use of exogenous prostaglandins as effective and safe. However, in specific patient populations, such as those with vaginal births after cesarean section, the use of a Foley's catheter is a safer option. No common side effects (intrapartum or postpartum fever and vaginal bleeding, the quite rare rupture of membranes, along with displacement of the presenting part and umbilical cord prolapse) have been seen with this simplified insertion technique in this study. Moreover, dinoprostone gel cannot be used in patients with medical disorders like bronchial asthma, epilepsy, and glaucoma in which Foley's catheter can be used safely for cervical ripening. However, dinoprostone gel use is associated with higher incidence of fetal distress and, hence, increased chances of abdominal delivery. Therefore, considering the side effects of dinoprostone gel, its irreversible effect on uterine contraction, cost, and requirement of proper monitoring of fetus and mother, it is better to use Foley's catheter with EASI than dinoprostone gel. It avoids the need for continuous monitoring in a health care facility. Hence, Foley's catheter is safe in contrast to dinoprostone gel. ${ }^{6}$

Foley's catheter causes less fetal distress. The safety profile of Foley's catheter is such that it can be used on an outpatient basis, but not dinoprostone gel. These results make Foley's catheter comparable or even superior to dinoprostone gel for cervical ripening, especially in developing countries. Thus, it is concluded that cervical ripening with EASI using Foley's catheter has the 
advantages of simplicity, low cost, reversibility, and lack of serious side effects.

\section{CONCLUSION}

Based on the findings of this study, it may be concluded that EASI using Foley's catheter has slightly higher success rate for cervical ripening for induction of labor as determined by Bishop's score of $\geq 6$ compared with intracervical dinoprostone gel. In addition, time taken for cervical ripening is significantly less with EASI using Foley's catheter. Though EASI Foley's catheter resulted in higher success rate with less time for cervical ripening, the rate of cesarean section is high.

Furthermore, the neonatal outcome in babies born to women undergoing EASI using Foley's catheter is comparable with those who have induction of labor with intracervical dinoprostone gel.

\section{REFERENCES}

1. Brindley BA, Sokol RJ. Induction and Augmentation of labor: basis and methods for current practice. Obstet Gynecol Surv 1988 Dec;43(12):730-743.

2. Vogel JP, Souza JP, Gülmezoglu AM. Patterns and outcomes of induction of labour in Africa and Asia: a secondary analysis of the WHO Global Survey on Maternal and Neonatal Health. PLoS One 2013;8(6):e65612.

3. Laughon SK, Zhang J, Grewal J, Sundaram R, Beaver J, Reddy UM. Induction of labor in a contemporary obstetric cohort. Am J Obstet Gynecol 2012 Jun;206(6):486.e1-486.e9.

4. Lydon-RochelleMT,Cárdenas V,Nelson JC,Holt VL, GardellaC, Easterling TR. Induction of labor in the absence of standard medical indications: incidence and correlates. Med Care 2007 Jun;45(6):505-512.
5. Sanchez-Ramos L. Induction of labor. Obstet Gynecol Clin North Am 2005 Jun;32(2):181-200, viii.

6. Dahiya K, Malik K, Dahiya A, Nanda S. Comparison of the efficacy of Foley catheter balloon with dinoprostone gel for cervical ripening at term. Int J Clin Med 2012 Nov;3(6):527-531.

7. St. Onge RD, Connors GT. Preinduction cervical ripening: a comparison of intracervical prostaglandin E2 gel versus the Foley catheter. Am J Obstet Gynecol 1995 Feb;172(2 Pt 1):687-690.

8. Ezimokhai M, Nwabineli JN. The use of Foley's catheter in ripening the unfavourable cervix prior to induction of labour. Br J Obstet Gynaecol 1980 Apr;87(4):281-286.

9. Goldman JB, Wigton TR. A randomized comparison of extraamniotic saline infusion and intracervical dinoprostone gel for cervical ripening. Obstet Gynecol 1999 Feb;93(2):271-274.

10. Schreyer P, Sherman DJ, Ariely S, Herman A, Caspi E. Ripening the highly unfavorable cervix with extra-amniotic saline instillation or vaginal prostaglandin E2 application. Obstet Gynecol 1989;73:938-942.

11. Rouben D, Arias F. A randomized trial of extra-amniotic saline infusion plus intracervical Foley catheter balloon versus prostaglandin E2 vaginal gel for ripening the cervix and inducing labor in patients with unfavorable cervices. Obstet Gynecol 1993 Aug;82(2):290-294.

12. Sherman DJ, Frenkel E, Tovbin J, Arieli S, Caspi E, Bukovsky I. Ripening of the unfavorable cervix with extraamniotic catheter balloon: clinical experience and review. Obstet Gynecol Surv 1996 Oct;51(10):621-627.

13. Levy R, Kanengiser B, Furman B, Ben ArieA, Brown D, Hagay ZJ. A randomized trial comparing a $30-\mathrm{mL}$ and an $80-\mathrm{mL}$ Foley catheter balloon for preinduction cervical ripening. Am J Obstet Gynecol 2004 Nov;191(5):1632-1636.

14. Rashid M, Begum A, Chowdhury SB, Chowdhury S. Induction of labor by Foley's Catheter method. A clinical study of forty cases. Bangladesh J Obstet Gynaecol 1994;9(1):16-21.

15. Leduc D, Biringer A, Lee L, Dy J; Society of Obstetricians and Gynaecologists of Canada. Induction of labour. J Obstet Gynaecol Can 2013 Sep;35(9):840-860. 